\title{
Al-Munäfarah's skills and it impact on the development of Arabic rhetorical thought
}

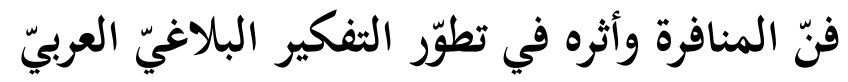

\section{Ayman Khamis A Abu Mustaffa}

aymanmostafa1982@gmail.com

Islamic University of Minnesota

The United State of America

• Received: 18.05.2021 • Accepted: 11.10.2021 • Published online: 25.11 .2021

Abstract: This study is concerned with standing on the bragging about our Arab heritage, an attempt to elucidate the impact of this art on the development of Arab rhetorical thought, as the brags can be an early start for the pilgrims' theory that came as the result of the effects of modern stylistic studies. The study tries to root and clarify this through heritage books, and this is not what makes us stand as the defender of heritage, but rather it is an attempt to link the old with the modern, as ancient Arab literature was not separate from life, but rather discussed life issues in a literary manner. Also, in this type of art, we notice the availability of dramatic elements that can be indicative of theatrical art for Arabs, so bragging is not just a speech, but rather a recitation, movement and interaction with the audience.

Keywords: Bragging, Arabs, Theater, Rhetoric, Linguistics, Munafara.

$$
\begin{aligned}
& \text { الملخص: تهتم هذه الدراسة بالوقوف على المفاخرة في تراثنا العربي، محاولة استجلاء أثر } \\
& \text { هذا الفن في تطور التفكير البلاغي العربي، فالمفاخرات يمكن أن تكون بداية مبكرة لنظرية }
\end{aligned}
$$

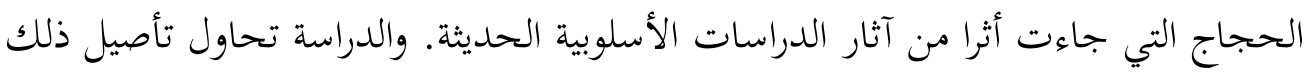

$$
\begin{aligned}
& \text { وتوضيحه من خلال كتب التراث، وليس في ذلك ما يجعلنا نقف موقف المدافع عن التراث، } \\
& \text { ولكن هي محاولة للربط بين القديم والحديث، فالأدب العربي القديم لم يكن منفصلا عن } \\
& \text { الحياة، بل كان يناقش قضايا الحياة بأسلوب أدبي. كما أننا في هذا النوع من الفن نلحظ }
\end{aligned}
$$


Ayman Khamis Abdullatif Abu Mustaffa

توافر العناصر الدرامية التي يمكن أن تكون مؤشرا للفن المسرحي عند العرب، فليست المفاخرة مجرد خطاب، بل هي إلقاء وحركة وتفاعل مع الجمهور. كلمات دلالية: مفاخرة، جدال، مسرح، بلاغة، لسانيات، وظيفة

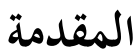

المفاخرات والمنافرات فن من الفنون التي اشتهرت عند العرب، وهي فن ذو أهمية في التأثير في بلاغتنا العربية، حيث إنها تكاد تكون النواة الأولى للفن المسرحي عند العرب، كما أنها اتسمت بالاستدلال والبناء الحجاجي، وهذا الفن برغم ثرائه لم يلق اهتماما من الدراسين، فالدراسات التي تناولته اهتمت بعرضه دون الربط بينه وبين القضايا البلاغية الحديثة، أو ذكر برك كونه النواة الأولى للاستدلال على حجاجية النص في التراث العربي.وهذا ما هدف إليه هذا

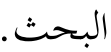

فقد هدف البحث لبيان أثر المنافرات في تطور الفكر البلاغي؛ حيث تبين أن لها أثرا كبيرا في النزعة الكلامية الحجاجية الاستدلالية، وهذا ما يجعلها صالحة للدراسات الحجاجية الحداثية، كما أنها كانت في شكل سجالي حواري، يتبادل المتنافرون فيه الحوار، وبينهما حكم يحكم بينهم، مما يجعله أقرب للمسرح بشكله الحديث. منهجية البحث

وقد اعتمدت في هذا البحث على المنهج التحليلي، حيث تتبعت الظاهرة (المنافرات) ثم رصدتها ثم حللتها معلال لها بقدر المستطاع، وذلك من خلال الوقوف على الظواهر الحجاجية والتداولية في النص، حيث إن التحليل الحجاجي يهدف إلى بيان أثر بناء النص

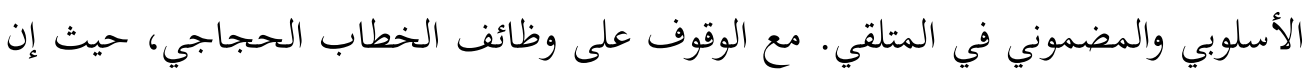
له وظيفتين: وظيفة إقناعية، ووظيفة سجالية، وله مجموعة من القوانين، منها ما يعود للمنطق، ومنها ما يعود إلى البلاغة، تهدف جميعها لتغيير قناعات المتلقي.

\section{نتائج الدراسة وتحليلها}


Ayman Khamis Abdullatif Abu Mustaffa

المنافرة لغة واصطلاحا: - ماح

المنافرة والمفاخرة خطاب أدبي يعتمد على الصراع بين طرفين، يرى كل منهما أحقيته

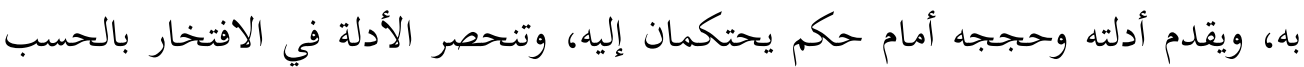
والنسب والأفعال والآباء والجدود، وسميت منافرة لأنهم كانوا يقولون عند المفاخرة أنا أعز

نفر ا. (Ṣiyām, 1978:201)

وتحديد مفهوم المنافرة سيكون ذا فائدة كبيرة في تحديد مفهوم مصطلح حجاج ، حيث إن كل كلام يتجة إلي المخاطب قصد إقناعة بفكرة ما و أستمالته إليها ، وبذلك يمتد هذا التعريف ليشمل المنافرات والمفاخرات.

والمنافرة في اللغة تشير لمعنى الصراع ، والمنافرة كما كانت تجري في الجاهلية، فهي

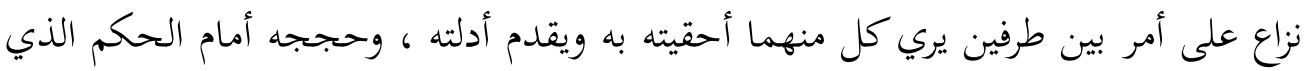
يحتكمان إليه للتدليل على ذلك وقد كانت تلك الأدلة تنحصر في الافتخار بحسبة وأفعاله ، ومفاخراً بآبائه وأفعالهم ، وسميت منافرة لانهم كانوا يقولون عند المفاخرة أنا اعز نفراً. Al (Al) Alusi, 2012:1/88)

فالمنافرة تعني التعصب للقبيلة والتفاخر بأيامها ووقائعها، وفي الوقت ذاته تفند آراء الخصم الذي يرى عكس ذلك، ومن أشهر المنافرات في التراث العربي منافرة علقمة بن علاثة العامري، وعامر بن الطفيل العامري، وهما عامريان تنازعا على الرياسة، وقد وردت المنافرة في الأغاني لأبي فرج الأصفهاني، وفي العقد الفريد لابن عبد ربه. ومن خلال دراستنا لهذا الفن نستطيع أن نقف على سبق التراث العربي إلى طريقة التعبير التي تأثرت بحياتهم العقلية، فكانت هناك طرائق في الاحتجاج تتفق مع ما جاء به علم الكلام بعد ذلك، أو ما أطلق عليه (المذهب الكلامي).

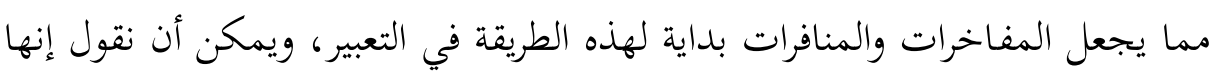
بذرة نظرية الحجاج التي جاءت أثرا من آثار الدراسات الأسلوبية الحديثة. وفي هذه الورقة البحثية سيحاول الباحث تأصيل ذلك وتوضيحه مستعينا بكتب التراث، مثبتا أن العودة إلى التراث هي المنطلق الصحيح لكل جديد. فالمنافرات في تراثنا كثيرة كما يبدو، ومنها منافرة 
Ayman Khamis Abdullatif Abu Mustaffa

طريف بن العاصي والحدث بن ذبيان ، ومنها المنافرة التي نحن بصدد الحديث عنها، كما أن عصر الجاحظ قد شهد صراعاً في المقارنة بين الديك والكلب ، فقد كان النظام المتكلم في رأس المدافعين عن الكلب على حين أن معبد كان علي رأس المدافعين عن

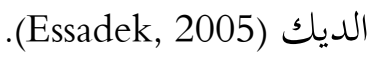

ونجد عند ابن عبد ربة في العقد الفريد عددا من المفاخرات التي دارت بين العرب

والفرس (Ibn 'Abd Rabbih, 1983:3/330-331) ، أما التوحيدي فيذكر في الإمتاع والمؤانسة مفاخرة جرت بين مجموعة من العرب، وابن المقفع كما يتولي التوحيدي في الكتاب نفسة الرد علي الحجهاني الذي يدعي تفوق الفرس على العرب (Al-Tauhīdī, 1953) كما

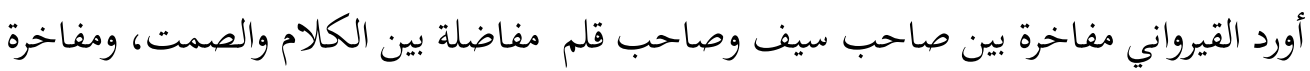
بين كتاب ونديم (Al-Qayrawani, 2017). كما أورد المسعودي مفاخرة بين البصرة والكوفة ومفاخرة بين مصر والبصيرة والكوفة. وقد أورد ابن النديم قائمة تتضمن كتبا مخصصة ، للمفاخرات منها : كتاب مفاخرات أهل البصرة وأهل الكوفة المدائني ت . ا ب هـ ، ومفاخرات العرب والعجم وكتاب مفاخرات

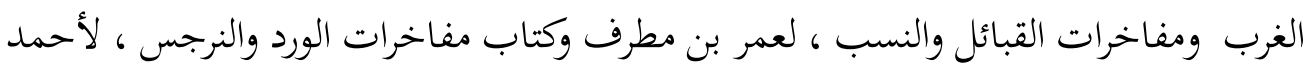
بن أبي ظاهر (Ibn al-Nadīm, 2009).

فالمنافرة هي المحاكمة في المفاخرة وأصلها من قولهم :أينا أعز نفرا، فهي التحاكم إلى

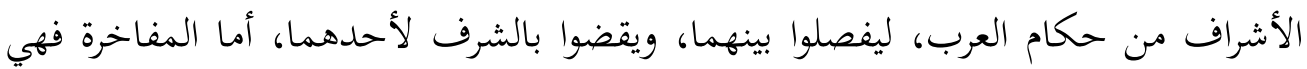
مصدر فاخر، وهي تفاخر القوم بعضهم على بعض، وكانوا يفاخرون بالحسب والشرف

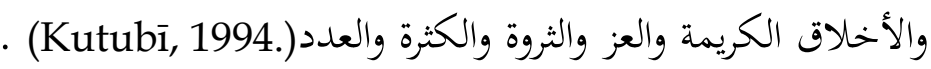
فالمنافرات فن من فنون الحوار عند العرب قبل الإسلام، فكان الرجلان إذا تنازعا في

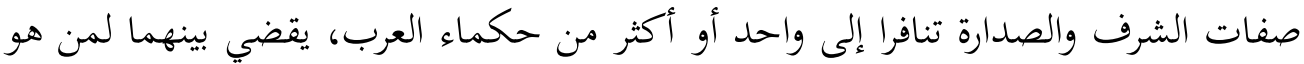
أحق بالصفات الكريمة والمآثر المشهودة ، ويذهب د.مصطفى الشكعة إلى أن من أسباب 
Ayman Khamis Abdullatif Abu Mustaffa

تسمية هذا اللون من الحوار بالمنافرات أن المحاور كان يقول لغريمه: أنا أعز منك نفرا، ويظل يذكر الدليل إثر الدليل، وكذلك يفعل غريمه إلى أن يحكم القاضي الذي اختاراه لواحد منهما. وكانت بعض ألوان المنافرات كما يذهب د.مصطفى الشعة تخرج عن المألوف، فتكون المفاخرة بالأموات، فيقول أحدهما: منا فلان ويشير إلى قبره، فيرد الثاني: ومنا فلان ويشير إلى قبره أيضا(Syak'ah, 1993).

\section{المنافرات ومقاصد الخطاب}

فخطاب (المنافرات والمفاخرات) يُعد رسالة لغوية، وعملية تواصلية ذات بواعث ومقاصد عدّة تقوم عليها العلاقات التخاطبية؛ وذلك لأنه " لا وجود لأي تواصل عن طريق العلامات دون وجود قصديّة وراء فعل التواصل, ودون وجود إبداع أو على الأقل دون وجود توليف للعلامات"(Dolo, 1994). فالمنافر يسعى جاهدا إلى أن يستثمر جميع الإمكانات السياقية، والطاقات اللغوية لنقل مقاصده عند إنتاج خطابه، فتتحول دلالة الخطاب من المعنى الظاهر الذي تدل عليه اللغة إلى معنى أو معان أخرى، بمعنى أن الخطاب في المنافرات ما هو إلا "علامة تنطوي عليها مقاصد المتكلم, وهذا ما يجعل معنى الخطاب يتعدد بتعدد السياقات التي ينتج فيها"(Syahri, 2004). ويتضح مما سبق من أن المقاصد والبواعث في العلاقات التخاطبية،هي الأساس لتساس المنتج في جميع الخطابات وبخاصة الخطاب الحجاجي، فلولا تلك المقاصد لما كان هناك حاجة لإنشاء الخطاب من قبل المتكلم، وإرساله إلى المتلقي. ومن أهم المقاصد والبواعث في خطاب (المنافرات)، الذي يهدف إلى الإقناع, هو الاختلاف Disagreement بين المخاطِب والمخاطَب، بل أنه يُعد الباعث والمحرك الأول للحجاج، فالحجاج لا يكون في أمر مأخوذ على أنه حقيقة يقينية راسخة،ولا يكون في أمر إلزامي واجب النفاذ، إنما يكون -

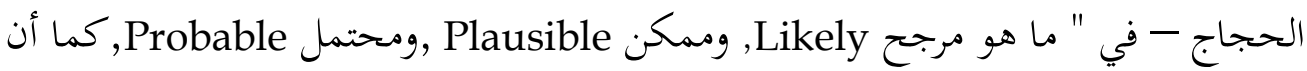
الأدلة التي تقدمها المحاجة ليس من شأنها أن تكون حاسمة فاصلة فيما تثبت أو تنفي، 
Ayman Khamis Abdullatif Abu Mustaffa

بحيث تقرر ما تقرره أو تنفي ما تنفيه على سبيل الحقيقة المؤكدة والراسخة التي لا تقبل شكا،

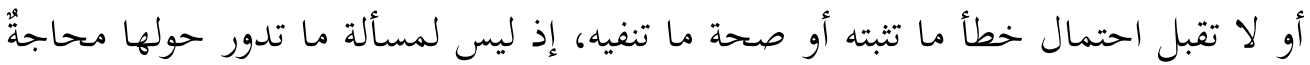

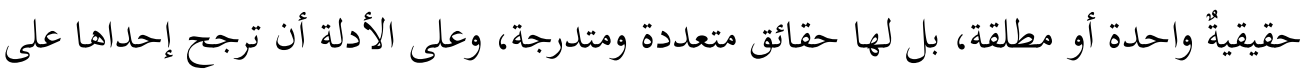
الأخرى، أو أن تصل إلى ما هو أقرب للصواب" (Majid, 2000). معنى ذلك أن الحجاج يكون فقط في الأمور الممكنة والمحتلة، لذلك يقدم المخاطِب حججه وأدلته، التي ترجح حقيقة واحدة، والتي غالبا ما تكون أقرب لصحة المسألة التي يحاجج فيها المخاطِب. ومن المقاصد التي تقوم عليها العلاقة التخاطبية، والتي تُعد من أهم بواعث الحجاج في الخطاب، هو "قصد التوجه إلى الآخر، وقصد إفهامه مرادا مخصوصا،

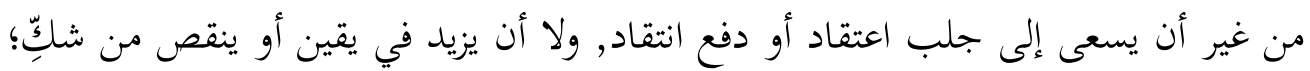
وإنما حقيقة الخطاب تكمن في كونه يضيف إلى القصدين التخاطبين المذكورين قصدين معرفيين هما: " قصد الادعاء" و "قصد الاعتراض"(Abdurrahman, 2002) . ويقتضي قصد الادعاء أن لا يكون المنطوق به خطابا حقيقيا، إلا إذاكان الناطق صريح الاعتقاد لما يقول من نفسه, ويكون على أتم الاستعداد لإقامة الدليل عليه عند الضرورة؛ ذلك لأن الخلو عن الاعتقاد يجعل الناطق, إما ناقلا لقول غيره, فلا يلزمه اعتقاده, وإما كاذبا في قوله, فيكون عابثا باعتقاد غيره, ولأن الخلو عن الاستعداد للتدليل, يجعل الناطق, إما متحكما بقوله, فلا يتوسل إلا بالسلطان, وإما مؤمنا بقول غيره, فلا يحتاج إلى برهان

(Abdurrahman, 2002) المنافرات والإقصاء التاريخي لا شك أن المنافرات واحدة من المرويات الجاهلية التي تعرضت للإقصاء والحجب، وذلك نظرا لتعارضها مع القيم الإسلامية، التي تنبذ خطاب القبلية والعصبية، وهي برغم ثرائها لم تنل حظا كبيرا من الدراسة ولعل انبناء تلك المنافرات والمفاخرات على أسلوب السجع كان سببا في إقصائها أيضا، حيث اتخذت المرويات الجاهلية أسلوب السجع القرآني فتلك الرويات رويت بصيغ مسجعة مطابقة في كثير من تفاصيلها لما جاء في النثر القرآني، هذا السجع الذي يقترن بالتتر الديني من قديم الأزل حيث يري بروكلمان أن السجع هو القالب 
Ayman Khamis Abdullatif Abu Mustaffa

الذي يصوغ العرافون والكهنة فيه كلامهم وأقوالهم) أي أن السجع أرتبط دائما بالنثر للإقناع

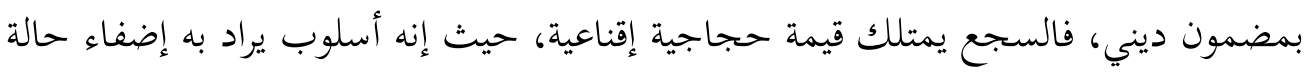

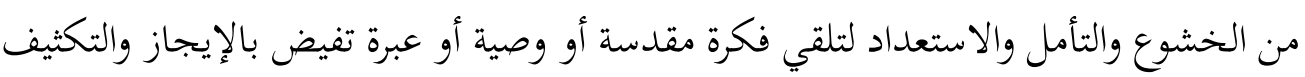

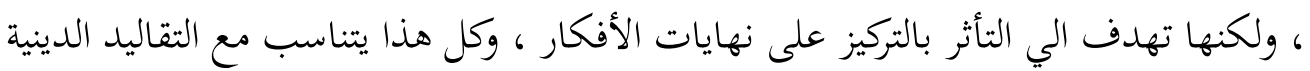

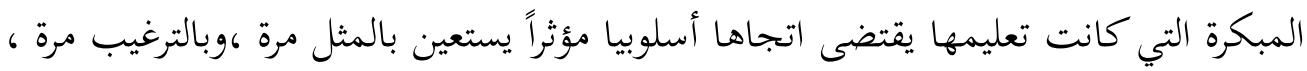
وبالترهيب إذا لزم الأمر وتنطوي الصيغة السجعية التي تتلاصق فيها الأفكار المثبوثه بانتظام في قوالب مرتبة على إمكانية تأثير كبيرة في المتلقي الذي يكون قد جاء في الأساس لتلقي أفكار محددة .

وسوف نقف على أشهر منافرة في العصر الجاهلي لتحليلها للخروج بمفهوم عام عن الحجاج وخصائصه في الجاهلية فهذه منافرة علقمة بن علاثة، وعامر بن الطفيل العامرين

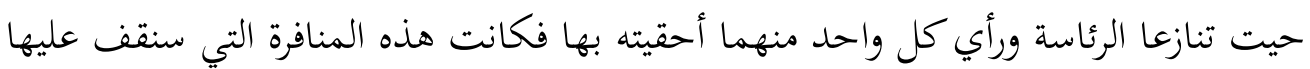
بينهما ، وقد كان علقمة شجاعا جوادا كريما وسيدا من سادات بني عامر وعلقمة هذا هو صاحب المنافرة مع عامر بن الطفيل، وكان علقمة أسخى من عامر وأوفى وأحلم، وعامر

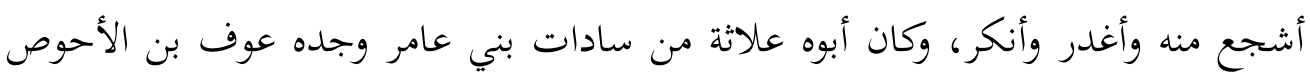

$$
\text { فارس العصا وجده الأحوص قائد هوازن. }
$$

المنافرة بين علقمة وعامر

حكى أبو عبيدة وغيره قال: أول ما هاج النفار بين علقمة بن علاثة وعامر بن الطفيل

أن علقمة كان ذات يوم قاعدا يبول فنظر إليه عامر، فقال: لم أر كاليوم سوءة رجل أقبح.

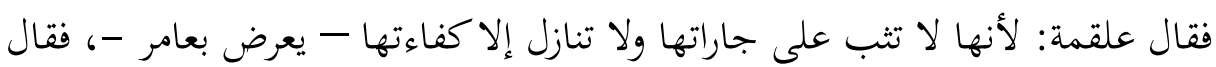

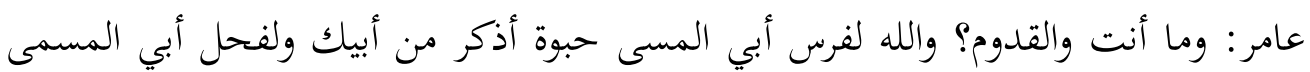

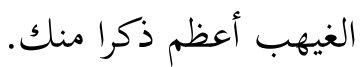
فقال علقمة: أما فرسكم فمعارة، وأما فحلكم فغدرة وكانوا قد استعاروا هذا الفحل من رحل بن كلب يستطرقونه فغلبوه عليه، ولكن إن شئ نافرتك. 
Ayman Khamis Abdullatif Abu Mustaffa

فقال علقمة: كانت لجدي الأحوص؛ وإنما صارت لعمك بسببه، وقد قعد عمك عنها، وأنا استرجعتها؛ فأنا أولى بها منك، فشرى الشر بينهما، وسار إلى المنافرة. فقال علقمة: إن شئت نافرتك؛ فقال عامر قد شئت. والله إني لأكرم منك حسبًا، وأثبت منك نسبكًا، وأطول منك قصبًا فقال علقمة: والله لأنا خير منك ليلاً ونهارًا؛ فقال عامر: والله لأنا أحب إلى إلى

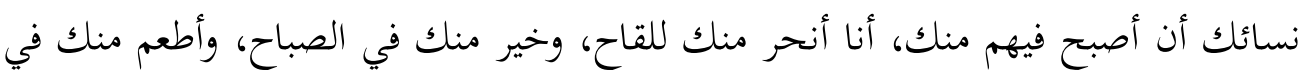
السنة الشياح.

فقال علقمة: أنا خير منك أثرًا، وأحد منك بصرًا، وأعز منك نفرًا، وأشرف منك ذكرًا؛ فقال عامر: ليس لبني الأحوص فضل على بني مالك في العدد، وبصري ناقص، وبصرك صحيح؛ ولكني أنافرك، إني أسمى منك سمة،وأطول منك قمة، وأحسن منك منك لمة لمة،وأجعد منك جمة وأسرع منك رحمة، وأبعد منك همة؛ فقال: علقمة: أنت رجل جسيم؛ فئ فقال عامر. آباؤك أعمامي، ولم أكن لأنافرك بهم لكني أنافرك، أنا خير منك عقبًا، وأطعم منك جدبكًا.

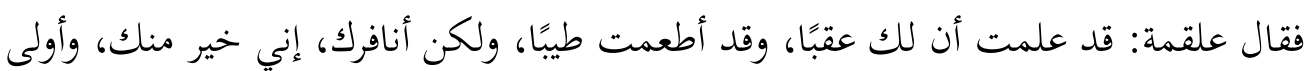
منك.

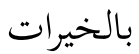

فخرجت أم عامر -وكانت تسمع كلامهما- فقالت: يا عامر نافره، أيكما أولى الخيرات. قال عامر: إني والله لأركب منك في الحماة، وأقتل منك للكماة وخير منك لمولى والمولاة: فقال له علقمة: والله إني لبر، وإنك لفاجر، وإني لولود، وإنك لعاقر، وإني لعف، وإنكك لعاهر،

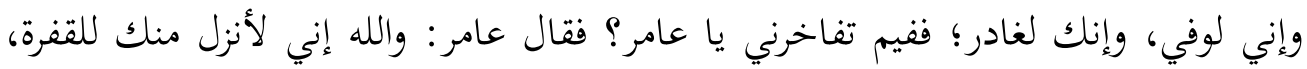
وأنحر منك للبكرة وأطعم منك للهبرة، وأطعن منك للثغرة؛ فقال علقمة: والله إنك لكليل البصر، نكد النظر، وثاب على جاراتك بالسحر.

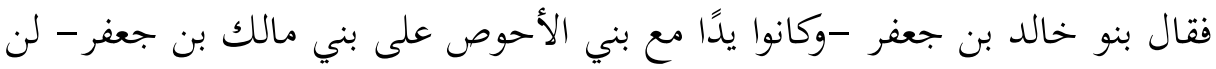

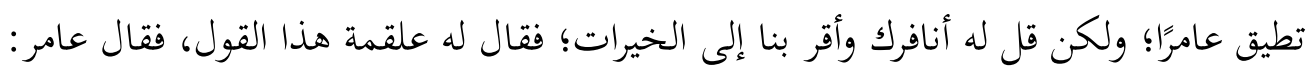

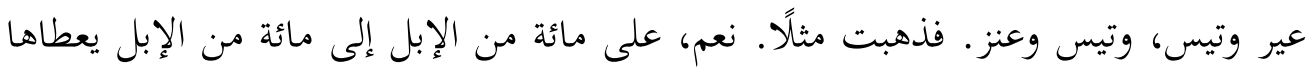


Ayman Khamis Abdullatif Abu Mustaffa

الحكم، أينا نفر عليه صاحبه أخرجها؛ ففعلوا ذلك، ووضعوا بها رهنًا من أبنائهم على يدي رجل يقال له خزيمة بن عمرو بن الوحيد؛ فسمي "الضمين."

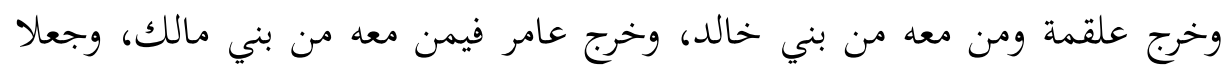
منافرتهما إلى أبي سفيان بن حرب بن أمية؛ فلم يقل بينهما شيئًا، وكره ذلك لحالهما وحال

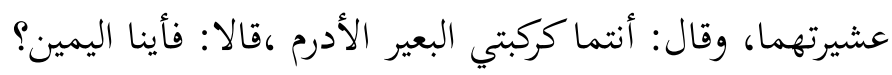

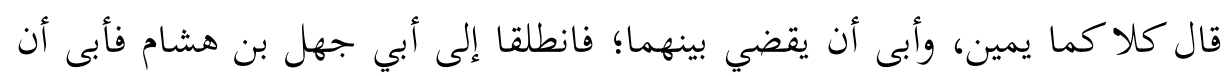

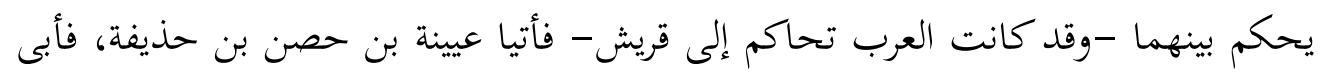

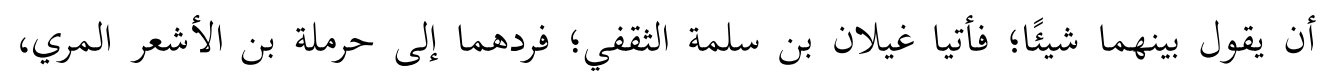

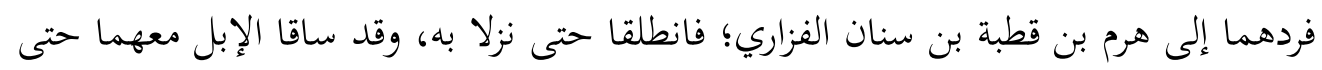

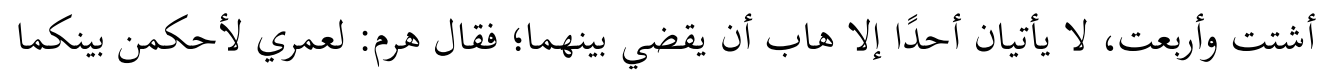

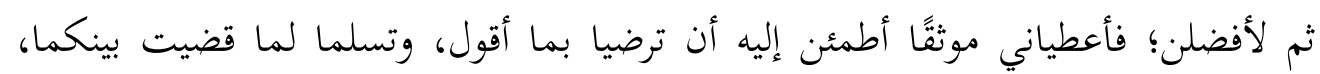
وأمرهما بالإنصراف، ووعدهما ذلك اليوم من قابل، فانصرفا، حتى إذا بلغ الأجل خرجا إليه، وأقام القوم عنده أيامًا.

فأرسل هرم إلى عامر فأتاه سرًا لا يعلم به علقمة؛ فقال يا عامر: قد كنت أرى لك رأيًا،

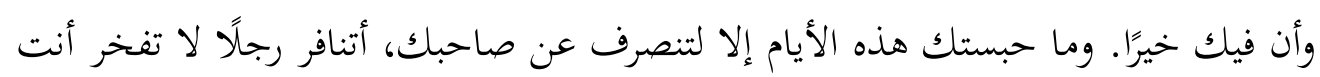

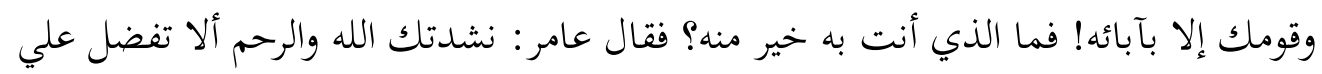

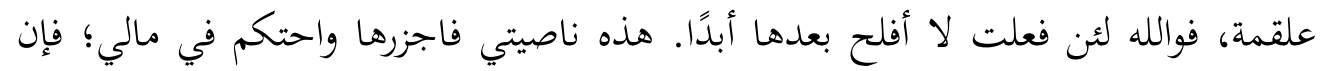
كنت لابد فاعلًا، فسو بيني وبينه، قال: انصرف فسوف أرى رأيي. فخرج عامر وهو لا يشك أنك

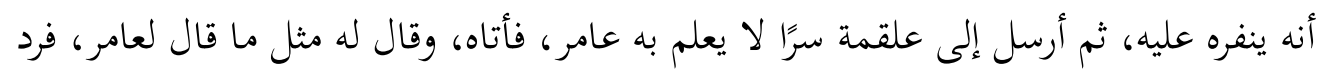

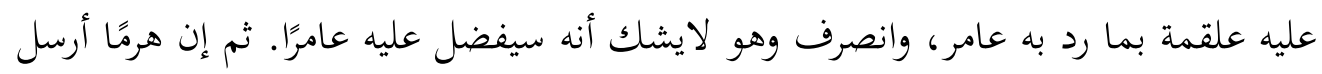
إلى بنيه وبني أبيه: إني قائل غدًا بين هذين الرجلين مقالة؛ فإذا فعلت فليطرد بعضكم عشر

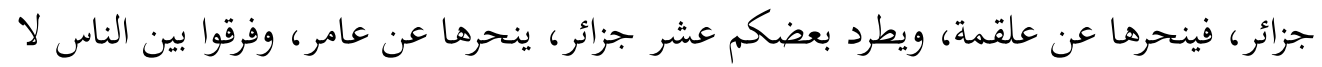

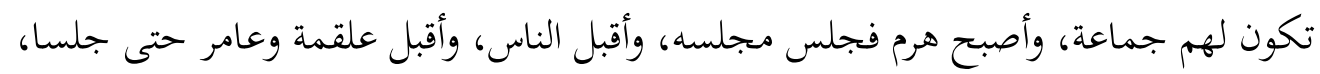


Ayman Khamis Abdullatif Abu Mustaffa

فقام هرم فقال: يا بني جعفر، قد تحاكمتما عندي، وأنتما كركبتي البعير الأدرم، تقعان على

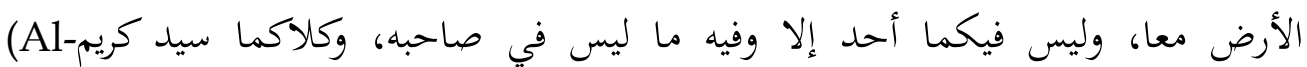
.Aṣfahānī, 1994)

\section{المنافرة وبلاغة الحجاج}

بالنظر إلى خطاب المنافرة نجد أن البعد الامتاعي يأتي تاليا للبعد الإقناعي، فلم يكن الخطاب ذا سمة امتاعية بل جاء محدد الغاية، واضح الهدف، متخذا من البلاغة وسيلة تمكينية للغاية الإقناعية، وهذا ما توصلت إليه البلاغة الجديدة أو بلاغة الحجاج، فهذا النمط من التعبير الحجاجي يقوم على احتجاج المتكلم على ما يريد اثباته، مستخدما حججا تؤيد

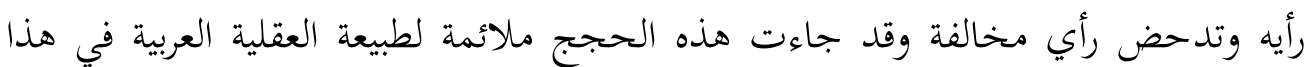
العصر، ولطبيعة حياتهم (Balbaa, 1969).

وانطلاقا من مسلمة د.أبوبكر العزاوي"لا تواصل من غير حجاج ولا حجاج بغير تواصل

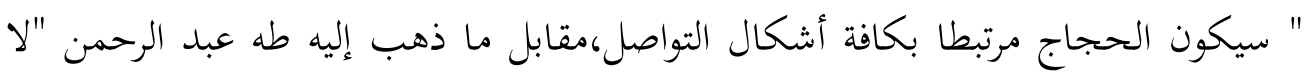
تواصل باللسان من غير حجاج ولا حجاج بغير تواصل باللسان" (Al-'Azāwy, 2010) حيث

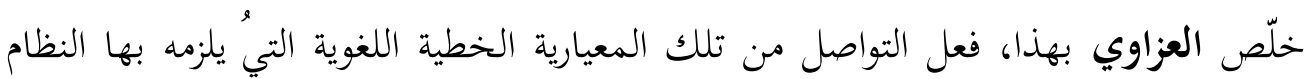
اللساني.

ومن هنا تلتقي المنافرات مع الخطاب الحجاجي، أو لنقل يلتقي الحجاج مع المنافرات، فقد شهد الدرس البلاغي في الدراسة المعاصرة، نقلة نوعية انطلاقا من العودة القوية للبلاغة، تحت مسمى (البلاغة الجديدة) والتي ارتبطت ببلاغة الحجاج على يد بيرلمان، وذلك من خلال مؤلفه " مقال في البرهان: البلاغة الجديدة"، والذي يعتمد فيه على محاولة إعادة تأسيس البرهان أو المحاجة الاستدلالية. وتُعد هذه الخطوة محاولةً لإقامة علم عام لدراسة الخطابات بأنواعها، ووصف خصائصها الإقناعية التي تسمح بإثارة تأييد الأشخاص للفروض التي تُقدم لهم أو تُعزز هذا التأييد. ولعل ما يميز البلاغة الجديدة عن غيرها من النظريات التي تهتم بالخطاب، هو أنها نظرية تسعى إلى الكشف عن بنية المعاني التي يتألف منها الخطاب؛ وهذا ناتج من تأثرها Indonesian Journal of Arabic Studies, Volume (3), Issue (2), November 2021 
Ayman Khamis Abdullatif Abu Mustaffa

بالمناهج اللسانية الحديثة التي تنظر إلى اللغة كنسق تتفاعل عناصره في إطار علائقي يرفض دراسة الكلمات في ذاتها(Badri, 2003) ؛ لذا اتسعت ميادينها - البلاغة الجديدةوأصبحت تشمل جميع الخطابات بما في ذلك الخطاب الشعري. فالحجاج او Argument لغة من حاج يحاج وهو تقديم الحجج والأدلة التي تؤيد

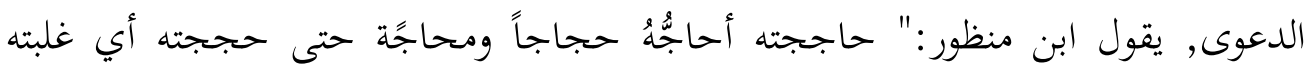
بالحجج التي أدليت بها ... وحاجّه محاجّه وحجاجاً نازعه الحجّة.... والحجّة الدليل والبرهان وقيل: الحجة ما دافع به الخصم... وهو رجل محجاج أي جدل, وحجّه يحجُّه حجَّاً: غلبه على حجَّته" (Ibn Manẓūr, 1993) ), إذن يأتي الحجاج مرادفا للجدل في في أحايين كثيرة كما

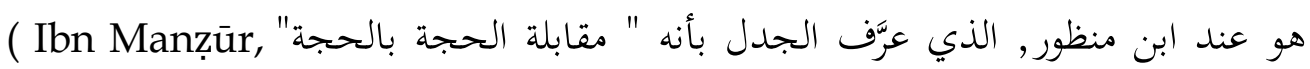
(1993, كما يأتي أيضا مرادفا للنزاع والخصام كما في قوله تعالى:" أَلَمْ تَرَ إِلَى الَّنِي حَاجَّ

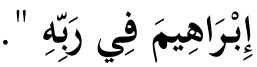

ويتبين لنا من خلال ما سبق أن الحجاج قد يأتي بمعنى الخصومة، أو الجدل، أو الغلبة، وكلها ألفاظ تجسد صورة الخطاب الحجاجي، فالخصومة بين الطرفين ينتج عنها الجدل الذي من خلاله تقام الحجج والبراهين، التي يستعين بها كل طرف في إثبات صحة ما يدّعي حتى تتحقق الغلبة له.

وتقترب الدلالة اللغوية من الدلالة الاصطلاحية للحجاج في الدراسات الفلسفية

الحديثة، والتي تتفق فيما بينها على كون الحجاج عملية اتصالية، تعتمد الحجة المنطقية (Majid, بالأساس- وسيلة لإقناع الآخرين والتأثير فيهم؛ لذلك يتخذ الحجاج مفهومين :2000)

أولا: طريقة تحليل واستدلال Reasoning, بقصد تقديم مبررات مقبولة للتأثير في

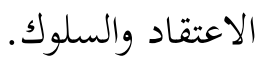
ثانيا: عملية اتصالية يُستخدم فيها المنطق Logic للتأثير في الآخرين. 
Ayman Khamis Abdullatif Abu Mustaffa

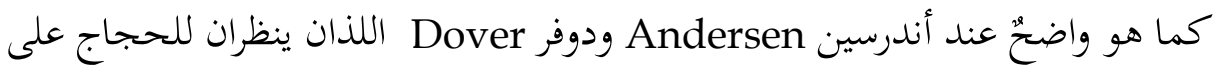

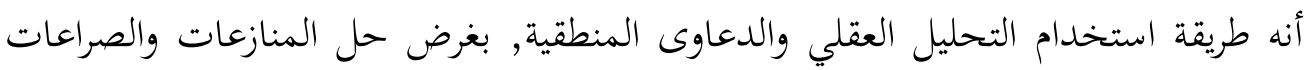

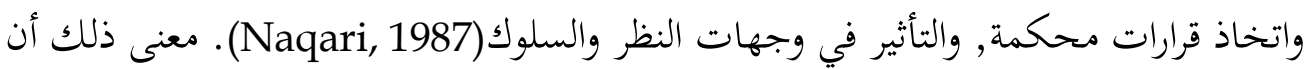
المحاجج يسعى لاستخدام المنطق بهدف التأثير في الآخرين وإقناعهم.

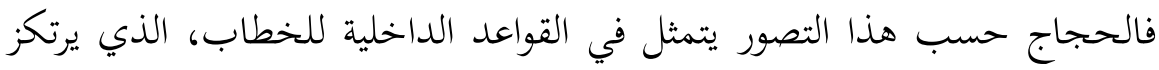
على اللغة، ويعتمد على مجموعة من الحجج تؤدي إلى نتيجة معينة؛ لذلك يتخذ الحجاج شكلا لغويا ومضمونا معرفيا.

وهو عند بيرلمان فهو "جملة من الأساليب تضطلع في الخطاب بوظيفة هي حمل

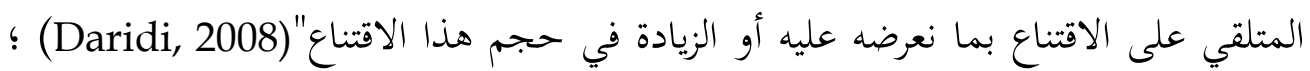
لذلك كان موضوع الخطابة الجديدة هو دراسة تقنيات الخطاب التي من شأنها أن تؤدي

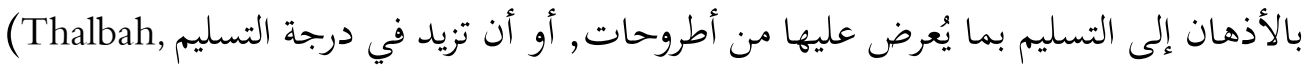
$.2008)$

والغاية من ذلك هو جعل العقول تذعن لما يطرح عليها أو يزيد في درجة الإذعان،

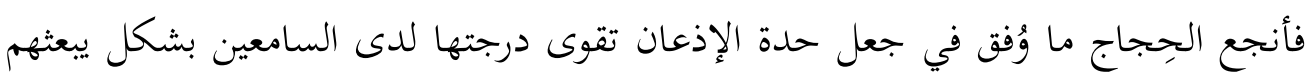

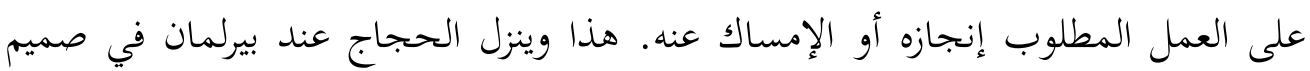

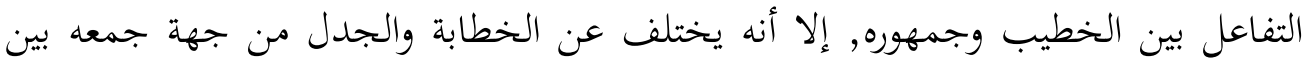

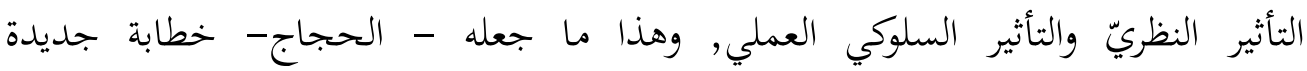
بالفعل) (Daridi, 2008).

ويبدو أن الغاية من الحجاج هي محاولة استمالة وإقناع شخص بالقضية المعروضة

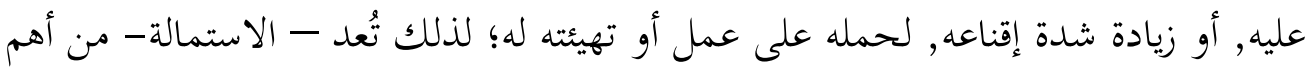

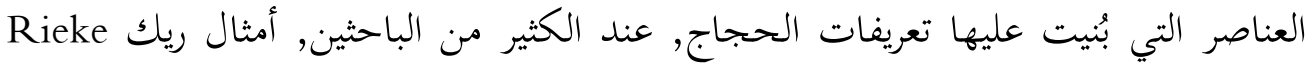

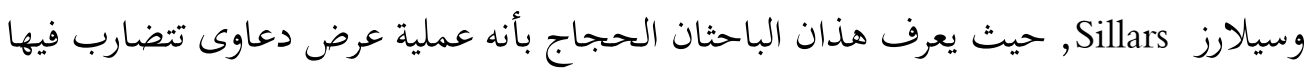


Ayman Khamis Abdullatif Abu Mustaffa

الآراء مدعومة بالعلل والدعامات المناسبة بغية الحصول على الموالاة لإحدى تلك الدعاوى(Daridi, 2008).

ويختلف الحجاج عند أزفالد ديكرو O.Ducrot, اختلافاً تاماً عن ما كان عليه عند بيرلمان, فالحجاج ينطلق عنده من الفكرة الشائعة التي مؤادها: (إننا نتكلم عامة بقصد التأثير), أي أنه يقوم أساساً على اللغة بل يكمن فيها, حيث يهتم بالوسائل اللغوية وبإمكانات اللغات الطبيعية التي يتوافر عليها المتكلم, وذلك بقصد توجيه خطابه وجهة ما, تمكنه من تحقيق بعض الأهداف الحجاجية (Al-'Azāwy, 2010). معنى ذلك أن اللغة تحمل بصفة ذاتية وجوهرية وظيفة حجاجية, فالحجاج باللغة يجعل الأقوال تتابع وتترابط على نحو دقيق فتكون بعضها حججا تدعم وتثبت بعضها الآخر (Daridi, 2008), أي أن المتكلم قد يصرّح بالنتيجة وقد يخفيها فيكون على المتلقي استنتاجها لا من مضمون هذه الأقوال الإخبارية بل اعتماداً على بنيتها اللغوية.

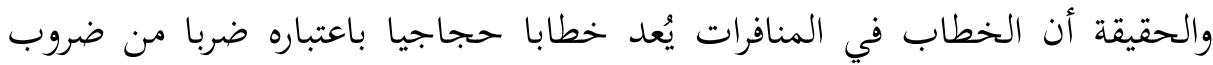

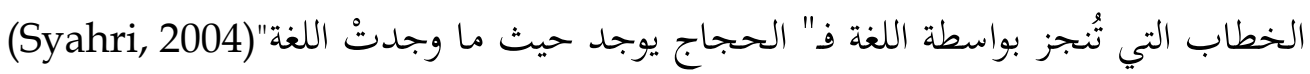
ويأتي الحجاج في الخطاب هنا على هيأة سجالٍ بين طرفين كل منهما يحاجج الطرف الآخر. استراتيجيات الحجاج في المنافرات تتمثل استراتيجيات الحجاج في ثلاثة وجوه هي:

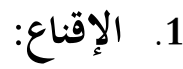

يتأسس الخطاب الحجاجي على استراتيجية الإقناع؛ لأن من أهم الأهداف التي يرمي المرسل إلى تحقيقها من خلال خطابه هو إقناع المرسل إليه بما يراه, أي " إحداث تغيير في

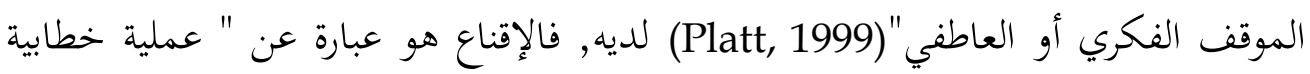
يتوخى بها الخطيب تسخير المخاطب لفعل أو ترك بتوجيهه إلى اعتقاد قول يعتبره كل منهما أو يعتبره الخطيب شرطا كافيا ومقبولا للفعل أو الترك"(Syahri, 2004). 
Ayman Khamis Abdullatif Abu Mustaffa

فمهما كانت مقاصد المخاطِب وغاياته, التي يروم تحقيقها في خطابه الحجاجي,

فإنها لا تتأتى إلا من خلال استراتيجية الإقناع الذي يُعد غاية الحجاج وهدفه, لذلك لابد أن يجند - المخاطِب- كل جزيئات القول ودقائقه, التي من شأنها إحداث " أثر ما في المتلقي أي إقناعه بفكرة معينة وهو ما يعبر عنه اللسانيون بالوظيفة الإيحائية (Conative) للكلام" (Daridi, 2008).

والمخاطِب يتتبع في تحصيل غرضه " سبلا استدلالية متنوعة تجر الغير جرّا إلى الاقتناع برأيه... وقد تزدوج أساليب الإقناع بأساليب الإمتاع, فتكون, إذ ذاك, أقدر على التأثير في اعتقاد المخاطَب, وتوجيه سلوكه"(Abdurrahman, 2002), كما هو حاصل في حجاج الخطاب الشعري. هذا وتتحدد مكونات العملية الإقناعية بطرفي الخطاب, وبفعلهما في صوغ الحجة وإبطالها, بالإضافة للصفات الدلالية كالأدلة والدعاوي؛ لذلك انصب جهد بيرلمان وتيتيكاه على التفاعل بين الباثٌ والمتلقي في الخطاب الحجاجي. فالخطاب الحواري متعدد الأصوات ، يعمد إلى المقارنة بين أكثر من شيء ، والنظر من زاوية الآخر ، غايته التأثير والإقناع ،"ومعلوم أن بلاغة الإقناع لا تقوم إلا في علاقة بالآخرين ولا تشتغل إلا حيث يشتغل الحوار"(Adil, 2013) . ونلاحظ قدرة المنافر المفاخر في

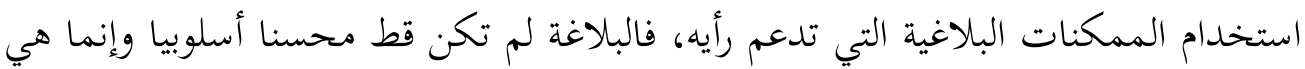
وسيلة ناجعة لإنجاز الأفعال، فقد استطاع من خلالها أن يستثير حفيظة المتلقي وأن يقنعه

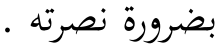

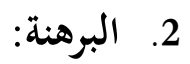

هي من الاستراتيجيات التي يلجأ إليها المخاطِب في خطابه الحجاجي, وذلك من أجل تحقيق عملية الإقناع, والتأكيد على صدق ما يدعيه, فالبرهنة في أبسط صورها هي

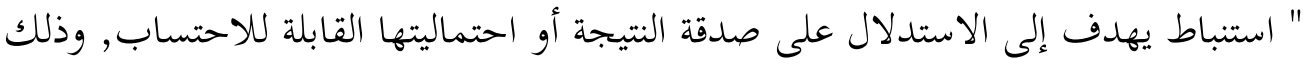
انطلاقا من المقدمات المعتبرة صادقة أو محتملة"(Habasyah, 2010). إذن تستخدم البرهنة في الاستدلال على صدق أو احتمالية ما يدعيه المخاطِب. هذا وتتمثل البرهنة في " الأمثلة 
Ayman Khamis Abdullatif Abu Mustaffa

والحجج وكل تقنيات الإقناع مرورا بأبلغ إحصاء وأوضح استدلال وصولا إلى ألطف فكرة وأنفذها"(Daridi, 2008). معنى ذلك أنها عملية فكرية انتقالية ينتقل فيها المخاطِب من ون العام إلى الخاص, من خلال عرضه للأمثلة والحجج والأدلة, التي يسوقها في خطابه بهدف إقناع المخاطَب.

وتلعب البرهنة دورا كبيرا في تطعيم الحجاج من الجهة الفنية, بالأساليب الأدبية البلاغية, كما أنها من جهة ثانية " أقرب إلى التربية منها إلى الدعاية ففي حين يكون موضوع التربية مما يقر به الجمهور ويعتقده ويؤمن به, فإن موضوع الدعاية يكون جديدا على أذهان الجمهور , والنوع البرهاني غايته مجرد إنشاء الاستعداد للعمل, شأنه في ذلك شأن الحطاب التربوي"(Thalbah, 2008). إذن الغاية من البرهنة هي التحفيز على العمل والاستعداد له.

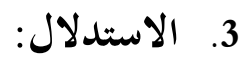

تعد استراتيجية الاستدلال من الأطر المكونة للحجاج والمحيطة به؛ لذا لا يمكنهالحجاج- الاستغناء عنه, فهو يمثل السياق العقلي له أي " تطوره المنطقي ذلك أن النص الحجاجي نص قائم على البرهنة فيكون بناؤه على نظام معين تترابط فيه العناصر وفق نسق تفاعلي وتهدف جميعا إلى غاية مشتركة, ومفتاح هذا النظام لساني بالأساس فإذا أعدنا النص الحجاجي إلى أبسط صوره وجدناه ترتيبا عقليا للعناصر اللغوية, ترتيبا يستجيب لنية الإقناع" (Daridi, 2008).

معنى ذلك أن الاستدلال يرتبط ارتباطا وثيقا بالبرهنة والإقناع, حيث أن ترتيب

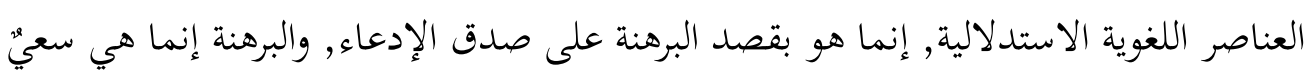

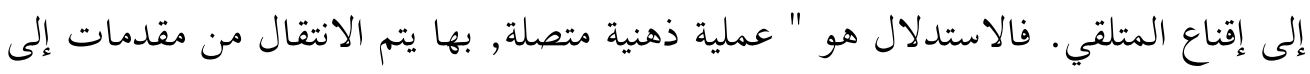
نتائج بالاستناد إلى علاقة منطقية تربط الأولى بالثانية"(Ar-Rifi, 1998), بمعنى أن الاستدلال هو أن تُستنبط النتائج من المقدمات, دون لبس ولا غموض. هذا ويقتضي الاستدلال أن تكون عناصره المكوِّة له غير قائمة على التعدد والاشتراك, فهي أحادية المعنى بحيث تكون العناصر مما يفهمه كل الناس, ولا يثير تأويلها 
Ayman Khamis Abdullatif Abu Mustaffa

أي خلاف لديهم(Ar-Rifi, 1998).وقد يكون الاستدلال بالقياس عن طريق إخراج الجزء من الكل, أو يكون بالاستقراء عن طريق إخراج الكل من الجزء, أو بالتمثيل عن طريق إخراج الجزء الخفي من الجزء المعروف.

ولعل النوع الأخير وهو الاستدلال بواسطة التمثيل, هو أقرب أنواع الاستدلال إلى

الشعر , وألصقها بجوهره باعتباره قائما على التخييل, فالاستدلال بواسطة التمثيل هو تشكيل بنية واقعية تسمح بإيجاد أو إثبات حقيقة عن طريق تشابه العلاقات(Daridi, 2008), بمعنى أن الاحتجاج عن طريق الاستدلال بالتمثيل, إنما يتم عن طريق علاقة الشبه التي تربط بين الأمر الذي يحتج له المخاطِب بأمر آخر.

ونخلص بعد ذلك إلى القول أنه يمكن معرفة الاستراتيجية المتبعة في الخطاب

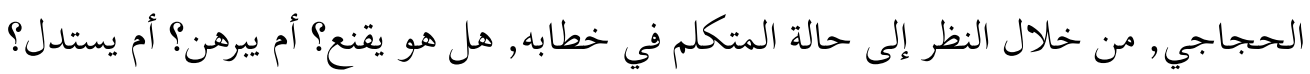
وأول ما يلفت النظر في هذه المنافرة هو الطابع الخاص في الاستدلال، حيث يضع

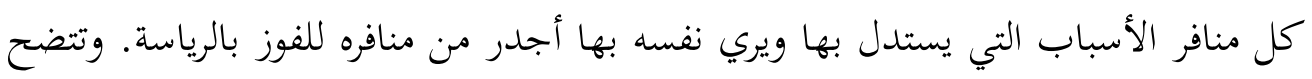
أيضا قدرة المنافرة في محاولة اقناع الحكم الذي يحتكمان إليه، باحقيته في الأمر دون منافرة.

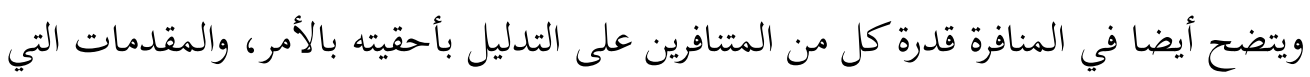

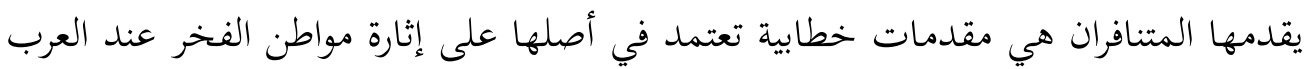
في الجاهلية.

وهذه المقدمات تعطي صورة أولية الاحتجاج في نثر ذلك العصر(Naufal, 1980)، حيث جاءت ملائمة للمثل السائدة فيه ،مع اعتمادها علي الترتيب العقلي بصور ملائمة لطبيعة العقلية العربية ، حيث تستخدم الاستدلال بمعناه العام ، حيث إن طور البداوة الذي كانت تمر به العرب في الجاهلية يتجلى فيه ضعف التعليل ، بمعني عدم القدرة على فهم الارتباط

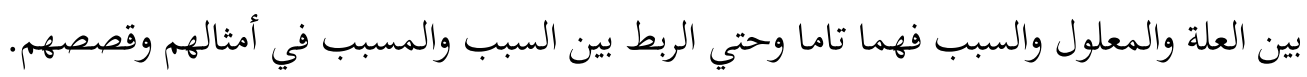
ومن ذلك: الرياسة كانت لجدي الأحوص. 
Ayman Khamis Abdullatif Abu Mustaffa

صارت لعمك بسببه ثم قعد عنها

أنا أولى بها منك

والمنافرة قائمة على أسلوب الاستدلال، من خلال ذكر الصفات التي تدل على أحقية

كل منهما.

تقنيات ووسائل الحجاج في المنافرات

يمكن تقسيم أهم تقنيات الحجاج ووسائله إلى:

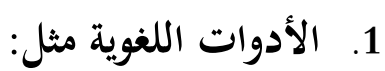

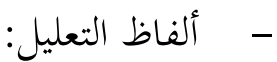

تُعد ألفاظ التعليل من الأدوات اللغوية التي يستعملها المخاطَب لتركيب خطابه

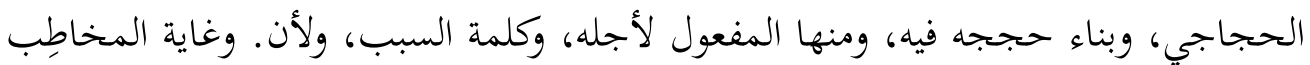
من استعمال هذه الأدوات هو تبرير أو تعليل لفعله, بناءً على سؤال ملفوظ به أو وله

مفترض(Syahri, 2004).

ومن ذلك قول علقمة (لأنها لا تثب على جاراتها ولا تنازل إلا كفاءتها)، حيث كان

علقمة ذات يوم قاعدا يبول فنظر إليه عامر، فقال: لم أر كاليوم سوءة رجل أقبح. فقال علقمة: لأنها لا تثب على جاراتها ولا تنازل إلا كفاءتها - يعرض بعامر .فجملة الرد على حجة عامر

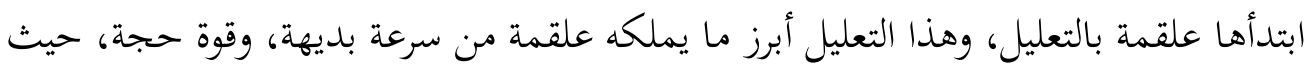

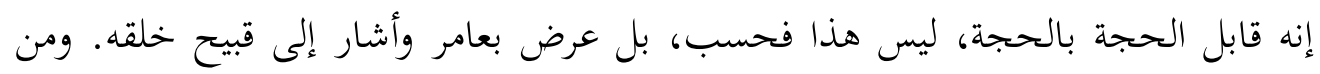
الأدوات اللغوية أيضا: أدوات الوصل - التركيب الشرطي - الأفعال اللغوية ، والأمثلة عليها كثيرة في المنافرة موضع الدراسة، من الشرط قول علقمة "إن شئت نافرتك، فقال عامر :قد "شئت

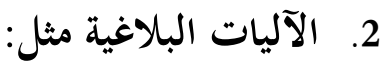


Ayman Khamis Abdullatif Abu Mustaffa

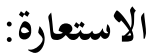

تُعرف الاستعارة الحجاجية "بكونها تلك الاستعارة التي تهدف إلى إحداث تغيير في الموقف الفكري أو العاطفي للمتلقي"(Okan, 2001) ؛ لذلك يفضل المخاطِب استعمالها في خطابه الحجاجي؛ لثقته بأنها أبلغ من الحقيقة حجاجيا في تحقيق الاقتناع, وتقويم الواقع والسلوك, وذلك من خلال ارتكازها على المستعار منه. وتكمن حجاجية الاستعارة في تدخل آليتي الادعاء والاعتراض, وذلك عن طريق الرضا بشروط كل من المخاطِب والمخاطَب, وبلورتها في الذوات الأربع, فالوظيفة الحجاجية للذات المضمرة هو إدعاء المعنى المجازي للخطاب, أي المباينة بين المستعار له والمستعار

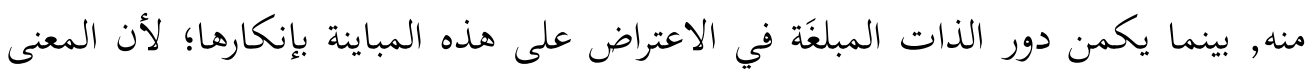
المبلغ هو الأولى بالظهور من المعنى الحقيقي غير المبلغ (Syahri, 2004). ومن ذلك استعارة الكينونة للرياسة في قول علقمة" كانت لجدي الأحوص، وإنما صارت لعمك بسببه، وقد قعد عمك عنها..." فكأن الرياسة هنا شيء مادي ينتقل من يد

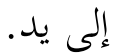

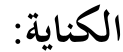

ترتبط الكناية بالجانب التداولى نظرا لما تحمله من معانى مضمرة مقصودة فقد عرَّف

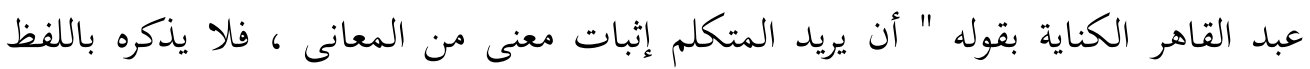
الموضوع له فى اللغة ، ولكن يجئ إلى معنى هو تاليه وردفه فى الوجود ، فيومئ به إليه ،

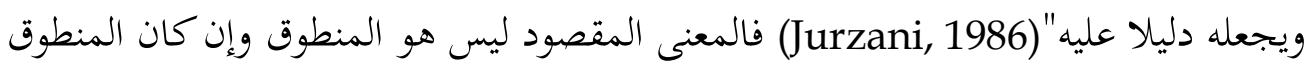
صحيحا غير مرفوض ويعد ذلك المنطوق دليلا على المعنى المقصود فالمعنى المقصود فى الكناية هو من قبيل المعانى الثوانى التى تناولها عبد القاهر ، " فالسيرورة التأويلية فى الكنايات القريبة بسيطة إذ ينتقل المؤول من الملفوظ إلى المقصود مباشرة لتنحد بذلك عملية التأويل

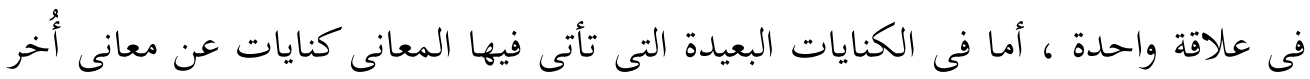

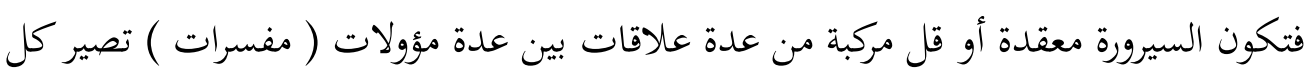


Ayman Khamis Abdullatif Abu Mustaffa

مفسرة منها علامة تحيل إلى معنى ( مفسرة ) ليصبح هذا المعنى ( المفسرة ) علامة تحيل

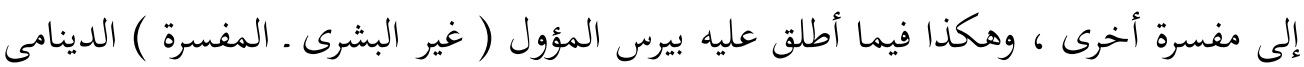

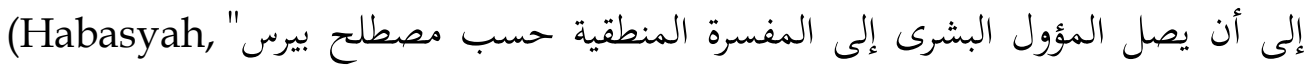
.2010)

فالكناية وسيلة استدلالية تنتقل بالمتلقي من مذكور لمستنتج، عبر سلسلة من الاستدلالات، وقد كثرت في المنافرات، ومن ذلك "وقد قعد عمك عنها" و" إني لأنحر منك لك

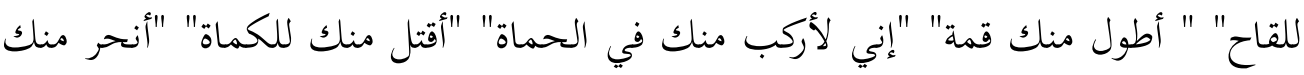
للبكرة"

\section{التوكيد:}

التوكيد سمة أسلوبية بارزة فى المنافرات فإذا كان التوكيد يستخدم مراعاة لحال المتلقى

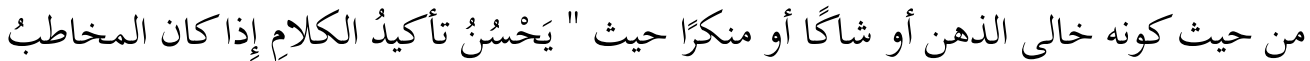

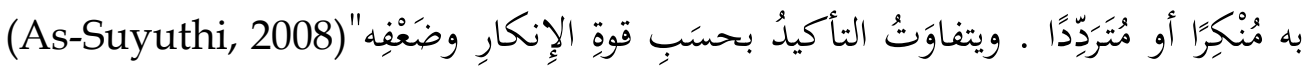

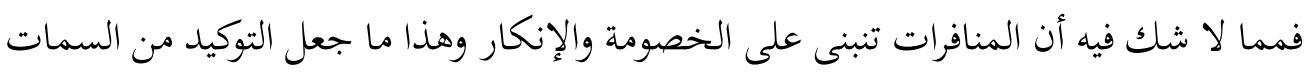

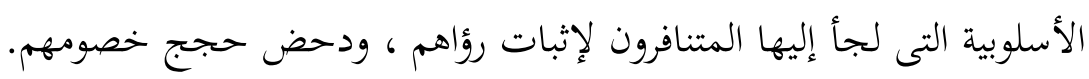
فقول عامر جاء مؤكدا بهذه الوسائل التي تؤكد أحقيته ( التأكيد بالقسم وإن ولام التأكيد وتقديم متعلق التمييز في جملة (والله إني لأكرم منك حسبا) ومن ثم جاء تأكيد علقمة موازيا مساويا لتأكيد عامر بل زاد عليه، (والله لأنا خير منك ليلا ونهارا) فقد استخدم نفس الوسائل مع إدخالها في أسلوب التضاد، وهكذا يظل التوكيد ضاغطا أسلوبيا ممكنا للغرض الحجاجي الذي انبنى عليه النص.

وقد تكرر التأكيد بقد وإن والقسم واللام ، والملاحظ أن (إن) يتبعا ضمير المتكلم(الياء) الذي يحمل سمة الفخر والاعتزاز بالنفس" إني أسمى.." " إني لأركب منك...

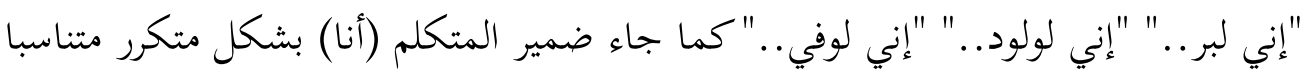
مع طريقة المنافرة " لأنا خيرمنك..." " لأنا أنحر منك..." . . 
Ayman Khamis Abdullatif Abu Mustaffa

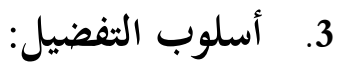

يدل أسلوب التفضيل على وجود أمرين أحدهما له أفضلية أكبر من الآخر فى الأمر

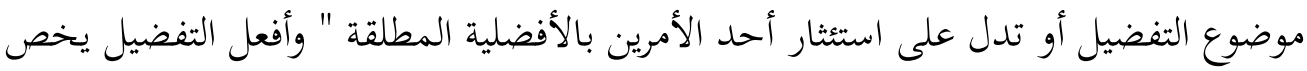
الثلاثيات المجردة الخالية عن الألوان والعيوب ، المبنية للفاعل نظير فعلى التعجب ، وله معنيان : أحدهما إثبات زيادة الفضل للموصوف على غيره والثانى : إثبات كل الفضل

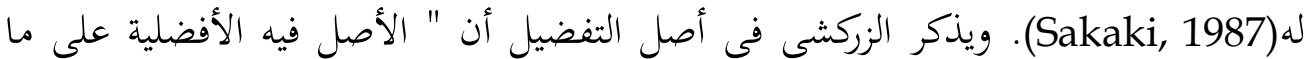
أضيف إليه " (Zarkasyi, 1968) فما ذكره الزركشى يجعل الأصل فى التفضيل هو زيادة المفضَّل على المفضَّل عليه فى صفة التفضيل بينما فصَّل التهانوى استخدام التفضيل للدلالة على الأفضلية المطلقة دون اشتراك من الطرفين فى الصفة يقول " قد يقصد بأفعل التفضيل تجاوز صاحبه وتباعده عن الغير فى الفعل لا بمعنى تفضيله بالنسبة إليه بعد المشاركة فى بـ أصل الفعل ، بل بمعنئ أنّ صاحبه متباعد فى أصل الفعل متزايد إلى كماله قصدًا إلى تمايزه عنه فى أصله مع المبالغة فى اتصافه ، بحيث يفيد عدم وجود أصل الفعل فى الغير ووجوده إلى كماله فيه على وجه الاختصار ، فيحصل كمال التفضيل ، وهو المعنى الأوضح فى الأفاعل (At-Tahawun, "فى صفاته تعالى إذ لم يشاركه أحد فى أصلها ، حتى يقصد التفضيل (1996 وسواء أقُصِد به زيادة الأفضلية أم الأفضلية المطلقة فإننا نجد أسلوب التفضيل ملائما لجوالمفاخرات التى يعمد كل طرف فيها إلى إعلاء رأيه والتقليل من رأى الطرف الآخر " ولا

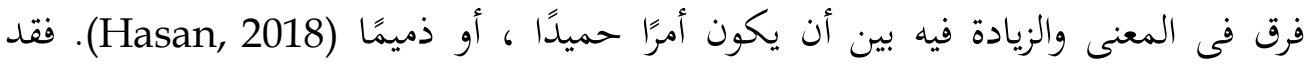
يستخدمه المنافر لإثبات الأفضلية لنفسه أو لرأيه أو لتسفيه رأى الآخر والزراية به حيث يهدف كل طرف إلى إثبات صحة رأيه مما لا يدع مجالا للخصم لنفى ذلك فيكون الاستمرار والدوام

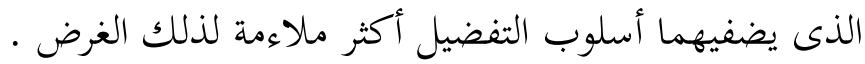

وقد يرتبط هذا الملمح بالبعد التداولى الذى يكشف عنه السياق سواء السياق اللغوى

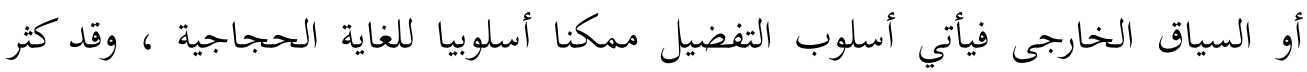
استخدامه في المنافرات، وقد تكرر في المنافرة بشكل واضح، ومن أسماء التفضيل في النص 
Ayman Khamis Abdullatif Abu Mustaffa

$$
\begin{aligned}
& \text { (لأكرم - أثبت - أطول - خير - أحب- أنحر - خير -أطعم - خير- أحد- أعز - } \\
& \text { أشرف- أطول- خير - أطول - أحسن - أجعد - أسرع - أبعد - أطعم - أولى - أركب - } \\
& \text { أقتل -أطعن ) }
\end{aligned}
$$

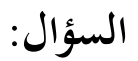

يعد السؤال من أبرز السمات الأسلوبية التى تنبنى عليها المنافرات، فالمنافرة فى

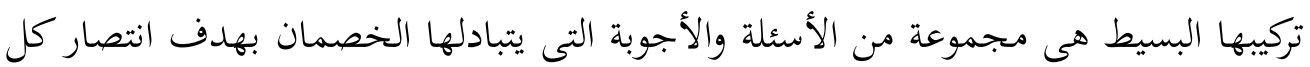

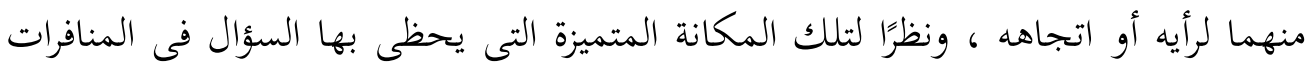

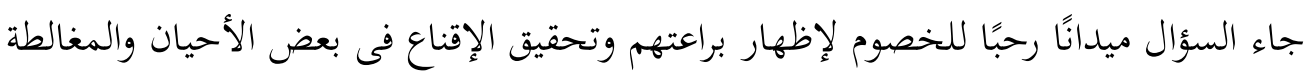
وإحراج الخصوم وإيقاعهم فى التناقض فى أحايين كثيرة . وقد ورد مصطلح الاستفهام معبرا عن السؤال متجاوزا دلالة طلب الفهم وقد ناقش دكتور عيد بلبع مفهوم المصطلح وتجاوزه فى كتابه أسلوبية السؤال(Balba' 1999) وآثرنا استخدام مصطلح السؤال متابعة له فى رؤيته. وأسلوب الاستفهام الذي نفضل فئل أن نطلق عليه السؤال قد جاء بعد مقدمات مؤكدة، جاء هذا السؤال ليدحض كل شبهة، ويقوي كل حجة، ويضعف موقف الخصم، يقول: فقال له علقمة: والله إني لبر، وإنك لفاجر، وإني لولود، وإنك لعاقر، وإني لعف، وإنك لعاهر، وإني لوفي، وإنك لغادر؛ ففيم تفاخرني يا عامر؟ ولا يغيب عنا تضافر هذا الأسلوب مع الازدواج والسجع، كما يتضافر مع التوكيد، وصيغة اسم الفاعل الصرفية. كما أن السؤال الذي سألاه لأبي سفيان حينما جاءا إليه يحتكمان

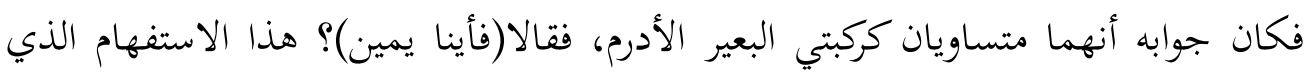
يقصد كل منهما من خلاله نيل الشرف وإدراك المرام، لكنه كان حكيما فقال(كلاكما يمين) وفي حيلة هرم بن قطبة بن سنان الفزاري نجد حضورا لسياق الموقف ، حيث أرسل لكل واحد منهما ليأتي منفردا، وقد بدأ الحوار بما يشد القلوب ، فيقول لعامر:" فقال يا عامر: قد بد بـ

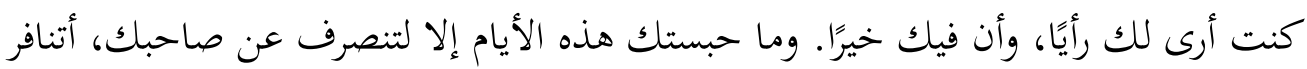

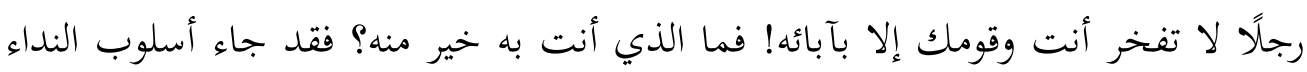


Ayman Khamis Abdullatif Abu Mustaffa

مرققا للقلب، جاذبا للنفس، ثم يقول له "قد كنت أرى لك ريا" وهذا يصدم عامرا ويجعله نادما على ما قدمه كي لا يفسد تلك العلاقة، ويهدم ذلك الرأي. وكان نتيجة ذلك أن أقرى عامر كما أقر علقمة منفردين بسبق كليهما، وهذا ما أراده هرم.

\section{البديع:}

يلجأ المخاطِب إلى استعمال بعض الأشكال البديعية، مثل: المقابلة، والجناس،

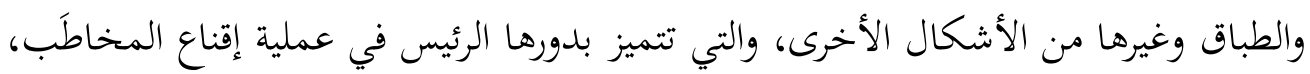
بالإضافة إلى دورها في زخرفة الخطاب.

فالهيكل الأسلوبي للسجع الذي التزم به الطرفان يضفي على المعنى جمالا يجعله أكثر

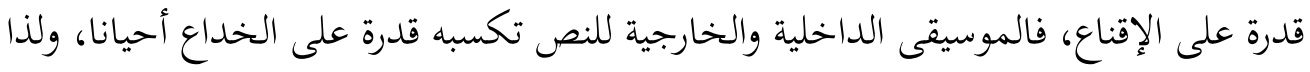
اعتمد عليها الكهان في صياغة تعاليمهم.

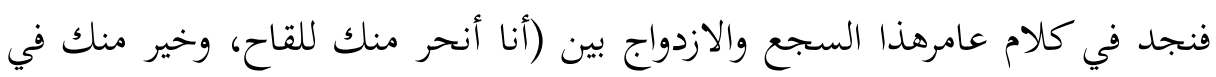
الصباح، وأطعم منك في السنة الشياح) فهذا الازدواج مع بنية السجع يجعل للكلام قبولا في نفس المتلقي.

فيرد علقمة بنفس الطريقة وعلى نفس المنوال (أنا خير منك أثرًا، وأحد منك بصرًا، وأعز منك نفرًا، وأشرف منك ذكرًا) فقد التزم هو الأخر نفس الطريقة، فجاء كلامه مسجوعا مزدوجا.

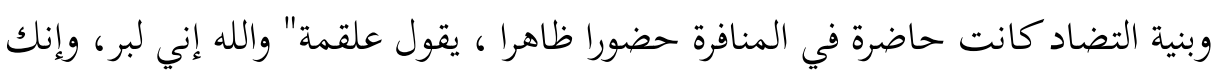
لفاجر، وإني لولود، وإنك عاقر، وإني لعف، وإنك لعاهر، وإني لوفي ، وإنك لغادر، وفيم

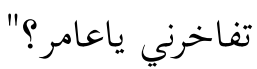

فهذه البنية التي تناغمت مع الدلالة، وانسبكت مع السؤال، قادرة على أن تشكل ضواغط أسلوبية على ذهن الخصم. كما أن الجناس الذي يقوم في بنائه على المشابهة اللفظية مع اختلاف المعنى يكون

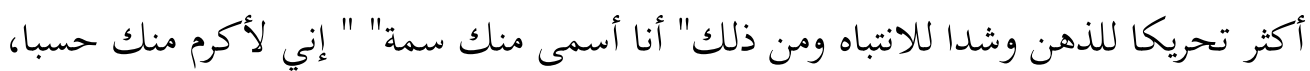
وأثبت منك نسبا" . 
Ayman Khamis Abdullatif Abu Mustaffa

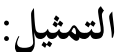

هو عبارة عن عقد الصلة بين صورتين, ليتمكن المخاطِب من الاحتجاج وبيان حججه(Syahri, 2004), ولعل ذلك يكثر في خطاب المنافرة لما يقوم به من تمكين للغاية الإقناعية، كما أن التشبيه بما يحمله من دلالة استدلالية يمكن للغاية الإقناعية، فالتشبيه هنا

$$
\begin{aligned}
& \text { (أنتما كركبتي البعير الأدرم) ينقل حكمة أبي سفيان، ويرد على المتنازعين. } \\
& \text { ثامنا: المنافرات وبواكير المسرح العربي }
\end{aligned}
$$

إن المنافرة تقوم على طرفين متنازعين، يحاول كلاهما الانتصار لنفسه، والنيل من غيره،

أمام حكم يحكم بينهما، وفي حضرة جمهور يتابع المشهد متحمسا، وهذا الجو الدرامي هو نواة المسرح والإبداع المسرحي، إن جاز لنا هذا الزعم.

والمنافرات عمل قائم على الحوار كما رأينا، ويمثل الحوار في البناء الدرامي المسرحي

دعامة رئيسة، بوصفه الناقل الأول والمباشر لجملة المخاطبات(répliques) المشفوهة التي

يحملها النص وتؤديها شخوص مجسدة على خشبة المسرح.

كما أن هيأة المنافر وقدرته على تمثيل معانيه يؤدي إلى إقناع الحكم ، وتلك الوظائف

التمثيلية ، هي الوظائف التي يتوخى من خلالها الكاتب المسرحي و المخرج نقل مقاصدهما الأدبية والفنية إلى الجمهور المتلقي.ومن هنا، فإن الحوار يقوم على تحقيق ثلاث غنائيات جوهرية وهي: تطوير الحبكة وذلك من خلال الانتقال المرحلي عبر محطات المنجز المسرحي من الاستهالال إلى العقدة إلى الحل، وكذا تقديم الشخصيات والتعريف بها من خلال جُملها الحوارية، وآخر هذه المهام هي تخلق الإمتاع في توليفاته الجمالية ضمن فعل الأداء والإلقاء. حيث تبرز عوامل ومقومات النطق الحسن المجهور الخالي من اللحن والعيّ التي قد تسهم في إشباع رغبة المتلقي الجمالية من خلال الإلقاء البليغ. فالحوار بهذا المعنى، "يشكل الظاهرة الفنية الثابتة التي

فالمؤلف المسرحي لن يجد أمامه سوى "الخوض في نمذجة تلك الأشكال السردية

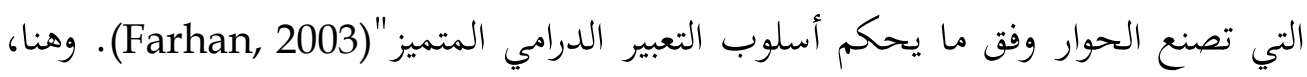


Ayman Khamis Abdullatif Abu Mustaffa

يلتجئ الكاتب إلى تلك الآليات الحجاحية التي أشرنا إليها سابقا. كما أن للسياق حضورا في العمل المسرحي، وهذا الحضور يضاهي حضوره في المنافرات، فنلاحظ ضرورة إبراز الملامح السياقية (الفلسفية، الإيديولوجية، الاجتماعية) للفعل الكلامي الذي يتحرك ضمنه الحوار المسرحي.

الخلاصة

يتبين لنا من خلال الدراسة السابقة أن التراث العربي الأدبي حافل بما يجمع بين المضمون القيم وطرائق التعبير التي لا تقل أهمية عن المضمون. فلم يكن الأدب في ذلك العصر صناعة لفظية فقط، وإنما كان قائما على الامتاع والإقناع، وكانت الغاية محركة ومؤثرة ، والاستدلال

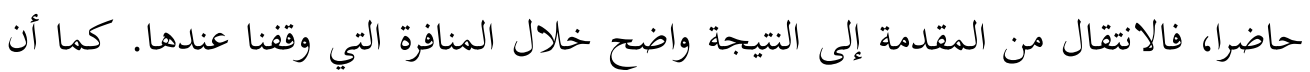
البلاغة لم تكن قط مجرد حلية لفظية، بل كانت متداخلة مع المعنى، ممكنة للغاية من الخطاب، وهذا ما ذهبت إليه البلاغة الجديدة. كما أن المنافرات تعد نواة المسرح العربي، فهي تقوم على فكرة النص والمتلقي والجمهور، وهذه المحاور (الكاتب) و(المرسل إليه) و(الجمهور) وقد امتدت هذه المنافرات وتطورت فكانت النقائض تطورا فنيا لها. وللسياق حضور في المنافرات يوازي حضوره المسرحي، حيث إن المتلقي يكون في حاجة إلى إدراك

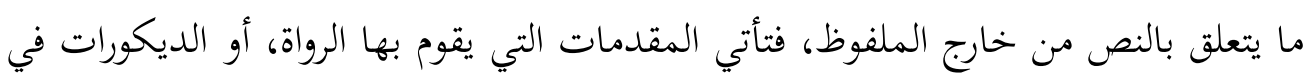
العمل المسرحي لتقوم بهذا الدور.

\section{المصادر والمراجع}

Abdurrahman, T. (2002). Lisan wa Mizan au Takawutsar Al Aqli. Darul Baidha.

Adil, A. (2013). Balaghah Iqna fil Munadoroh. Beirut-Lebanon: Mansurah Dhafaf.

Al-'Azāwy, A. B. (2010). Al-ḥ iț āb Wa Al Hạğāğ . Beirut: Al Rihab Publisher Est. 
Ayman Khamis Abdullatif Abu Mustaffa

Al-Alusi, M. S. (2012). Bulūg̀ al-Arb Fì Ma'rifä̈ Aḥ wāl al-'Arab. Cairo: Dār al-Kitāb al-Miṣ rī al-Lubnāni.

Al-Aṣ fahānī. (1994). al-Ag̉ānī (A. Al-Sibā'̄î, Ed.). Cairo: Mat aba'ä̈ alHai' ä̈ al-Miṣ riyyä̈ al-' āmmä̈ Lilkitāb.

Al-Mas'udi. (1978). Marūğ al-Dַahab Wa Ma'ādan al-Ğauhar (M. M. Abdelhamid, Ed.). Cairo: Maț ba'ä̈ Al-Sa'ādä̈ .

Al-Qayrawani, I. A. Z. (2017). Zahr Al-Adab Wa Tamr Al-Albāb (4th ed.; M. M. Abdelhamid, Ed.). Beirut: Dār Al-Ğ aīl Li-Našr Wa-ṭ abā’ä̈ Wā-Taūzì'.

Al-Tauh īdī, A. H. (1953). al-Imtā' wa al-Mu'āsä̈ (Aḥ md Amīn \& A. AlRīn, Eds.). Beirut: al-Naktabä̈ al-'Aṣ riyyä̈ .

As-Suyuthi, J. A. A. B. (2014). Al Itqan fi Ulum Qur'an (M. A. F. Ibrahim, Ed.). Cairo: Haiah Misriyah Al Amah lil Kitab.

At-Tahawun. (1996). Kasyaf Ishtilahat Al-Funun. Lebanon: Maktabah Libnan Nasirun.

Badri, F. (2003). Uslubiyah fi Naqd Hadits. Beirut-Lebanon: Majd Muassasah Jamiiyah.

Balba', 'Id. (1999). Ushlubiyah Sual Ruyah fi Tandir Balagi. Dar Wafa.

Balbaa, A. A. H. (1969). Al-Nat r Al-FannīWa Aț ar Al-Ğ āḥ iz Fìh. Cairo:

Lağ nä̈ al-Bayān al-Arabī.

Daridi, S. (2008). Al Hujaj fi Syi'ri Arabi. Oman: Jidar Lil Kitab Alami.

Dolo, G. (1994). Al-Taḥ lìl Al-Sìmìyūṭ ìqa Lin Naș Al-Ši'rī (A. Abū Ali, Trans.). Rabat: Imprimerie El Maarif Al Jadida.

Essadek, H. (2005). al-Munāz arä̈ Fì al-Adab al-'Arabì al-Islāmì. Beirut: Librairie du Liban Publishers. 
Ayman Khamis Abdullatif Abu Mustaffa

Farhan, B. (2003). An-Nash Al-MAsrahi Al-Kalimat wa Al-Fi'li. Damaskus: Ittihad Kitab Arabi.

Habasyah, S. (2010). Lisaniyyah Al-Khitab Al-Ushlubiyyah Wa At-Talafudz wa At-Tadawuliyyah (1st ed.). Suriah: DarAl-Hiwar Li An-Nasr Wa At-Tauzi.

Hasan, A. (n.d.). An nahwu al Wafi ma'a Rabth bil Asalib ar Rafiah wal Hayat Lughawiyah al Mutajaddidah. Mesir: Dar Ma'arif.

Ibn 'Abd Rabbih. (1983). al-'Aqd al-Farīd (2nd ed.; Aḥ mad Amīn, A. AlZaīn, \& I. Al-Ibyāri, Eds.). Beirut: Dar Kutub al-Ilmiyah.

Ibn al-Nadīm. (2009). al-Fahrasat (A. fuād Saīd, Ed.). London: Muassasä̈ al-Furqān liturāt al-Islāmi.

Jurzani, A. Q. Al. (1986). Dalail I'jaz. Kairo: Maktabah al Khanji.

Kutubi, Z. M. J. (n.d.). Fan Hiwar. Mekah: Mathabi Mahadir.

Majid, J. A. (2000). Al-Balaghah Wal Ittishal. Dar Gharib.

Mandur, I. (n.d.). Lisan Al-Arab. Kairo: Dar Al-Ma'arif.

Naqari, H. (1987). Haula Taqnin Aristo Li Thurq Iqna wa Masalikih. Majalah Kuliyah Adab Wa Ulum Insaniyah.

Naufal, W. (1980). Adz Dzahab Al Kalami fi Dars Balaghi. Jamiah Iskandariyah.

Okan, A. (2001). Al Lughah wal Khitab. East Africa.

Platt, H. (1999). Al Balaghah wal Ushlubiyah nahw Namudaj Simiyai li Tahlil Nash (M. Umr, Ed.). Beirut-Lebanon: Dar Baidha.

Rifi, H. (1998). Al Hujjaj inda Aristo: Mansur Dhimna Kitab Ahammu Nadhariyah Hujjaj fi Taqalid Gharbiyah min Aristo ila Yaum. Jamiah Adab wal Funun wal Ulum al Insaniyah Tunisia. 
Ayman Khamis Abdullatif Abu Mustaffa

Sakaki. (1987). Miftah Ulum. Beirut-Lebanon: Dar Kutub al-Ilmiyah.

Ș iyām, Z. (1999). al-'Adab al-'Arabī Fì Al-'Aș r Al-Ğähilī Wa Șadr AlIslām. Cairo: Dār Al-Naṣ r Liț ibā'ah Al-Islāmīyä̈ .

Syahri, A. H. D. (2004). Istrātīğ iyyāt Al-ḥ iț āb Muqārabä̈ Lug்aziyä̈ Tadāuliyyä̈ . Beirut: Dar Kitab Jadid Mutahidah.

Syahri, D. (2004). Istirotijiyat Al Khitob. Beirut-Lebanon: Dar Al-Kutub al-Jadidah.

Syak'ah, M. (1993). Al Adab fi Maukib Hadharah Islamiyah. Kairo: Dar Mishriyah Libnaniyah.

Thalbah, M. S. A. (2008). Al Hujjaj fi Balaghah Muashirah. Beirut: Dar Kitab Jadid Mutahidah.

Zarkasyi. (1968). Al-Burhan Fi Ulum al-Quran. Beirut-Lebanon: Dar Jail. 